\title{
T-matrix modeling of linear depolarization by morphologically complex soot and soot-containing aerosols
}

\author{
Michael I. Mishchenko ${ }^{\mathrm{a}, *}$, Li Liu ${ }^{\mathrm{a}, \mathrm{b}, * * *}$, Daniel W. Mackowski ${ }^{\mathrm{c}}$ \\ a NASA Goddard Institute for Space Studies, 2880 Broadway, New York, NY 10025, USA \\ ${ }^{\mathrm{b}}$ Department of Applied Physics and Applied Mathematics, Columbia University, New York, NY 10025, USA \\ c Department of Mechanical Engineering, Auburn University, AL 36849, USA
}

\section{A R T I C L E I N F O}

\section{Article history:}

Received 17 October 2012

Received in revised form

7 November 2012

Accepted 8 November 2012

Available online 19 November 2012

Keywords:

Soot aggregates

Optical cross sections

Linear depolarization

Remote sensing

Atmospheric radiation

\begin{abstract}
A B S T R A C T
We use state-of-the-art public-domain Fortran codes based on the $T$-matrix method to calculate orientation and ensemble averaged scattering matrix elements for a variety of morphologically complex black carbon (BC) and BC-containing aerosol particles, with a special emphasis on the linear depolarization ratio (LDR). We explain theoretically the quasi-Rayleigh LDR peak at side-scattering angles typical of low-density soot fractals and conclude that the measurement of this feature enables one to evaluate the compactness state of BC clusters and trace the evolution of low-density fluffy fractals into densely packed aggregates. We show that small backscattering LDRs measured with groundbased, airborne, and spaceborne lidars for fresh smoke generally agree with the values predicted theoretically for fluffy BC fractals and densely packed near-spheroidal BC aggregates. To reproduce higher lidar LDRs observed for aged smoke, one needs alternative particle models such as shape mixtures of $B C$ spheroids or cylinders.
\end{abstract}

Published by Elsevier Ltd.

\section{Introduction}

Black carbon (BC) and $\mathrm{BC}$-containing particles form a climatically important category of tropospheric aerosols exerting a direct radiative forcing of climate, inhibiting as well as facilitating cloud formation, and reducing the albedo of ice and snow surfaces, thereby affecting the overall energy budget of the terrestrial climate system [1-11]. They can also limit atmospheric visibility and have a highly negative effect on human health [12]. Owing to the notoriously complex morphology of such particles [13-30], theoretical modeling of their scattering and absorption properties is a highly nontrivial task and has often been based on approximate approaches with

\footnotetext{
* Corresponding author. Tel.: +1 212678 5590; fax: +1212678 5552 .

** Corresponding author at: NASA Goddard Institute for Space Studies, 2880 Broadway, New York, NY 10025, USA.

E-mail address: michael.i.mishchenko@nasa.gov (M.I. Mishchenko).
}

poorly defined accuracy and range of applicability. However, the growing need for much improved knowledge of $\mathrm{BC}$ and BC-containing aerosols and their climatic, ecological, and visibility effects imposes strict limitations on quantitative uncertainties in particle scattering and absorption properties entering optical characterization and remote sensing applications as well as atmospheric radiation budget computations [31-42].

Electron microscope images of soot particles show that they are emitted as complex chain structures (e.g., Ref. [16]), which tend to collapse upon humidification and/or as the particles age (e.g., Refs. [17, 22, 24, 43]), thereby changing their optical properties. Recently Ueda et al. [28] classified soot-containing particles into five major types: soot aggregates, dome-shaped particles, particles having satellite structures, single nearly spheroidal particles, and clusters of spheroidal units. R.K. Chakrabarty et al. (private communication) have conducted a literature survey and identified three major biomass burning aerosol habits: fractal soot aggregates, 
individual and semi-externally mixed tar balls [25], and carbonaceous super-aggregates [30] (we use the definitions of external, semi-external, and internal mixtures of particles according to Ref. [44]). One also encounters situations when soot clusters are semi-externally or internally mixed with other aerosol types [15, 27].

Some of the prevailing morphologies of BC and BCcontaining particles are illustrated in Fig. 1. One might think that the extreme complexity of these morphologies can limit one's ability to compute the scattering and absorption properties of realistic BC and BC-containing aerosol models with requisite accuracy. Yet the rapid growth of computer power coupled with the availability of efficient numerically-exact computer solvers of the Maxwell equations [45-48] has led to a recent explosion in the number of papers based on first-principle computations. The (superposition) T-matrix method (TMM) $[46,49-55]$ and the discrete dipole approximation (DDA) $[56,57]$ (or the closely related volume integral equation formulation $[58,59])$ appear to be the most frequently used techniques, as exemplified by Refs. [60-87] and [87-95], respectively. However, other approaches such as the finite difference time domain method (FDTDM), the pseudo-spectral time domain method, and the finite element-boundary integral technique are also gaining popularity [96-104].

It is commonly believed that the DDA and FDTDM provide greater flexibility in modeling complex particle morphologies. However, the currently available TMM codes (e.g., Refs. [46, 51, 105-107]) enable one to easily model the morphologies shown in Fig. 1a-d while providing much greater computational efficiency. Furthermore, it is expected that the superposition TMM code described in Ref. [105] will soon be extended to handle the internal mixing scenarios exemplified by Fig. 1e. Perhaps the only morphological detail that may defy the superposition TMM codes is partial overlap of otherwise quasispherical soot monomers resulting in so-called sintered soot aggregates. However, the results of Ref. [87] suggest that the effect of sintering on the scattering and absorption properties of soot aggregates is likely to be insignificant.

In our previous publications [44, 64-66], we had used the superposition TMM code described in Ref. [108] to analyze the potential effects of aggregation and heterogeneity on light scattering and absorption by complex tropospheric soot and soot-containing aerosols. The computations described below are based on the new Fortran 90 version of the code which makes use of dynamic memory allocation and vector arithmetic features that enable efficient execution on both parallel and serial machines $[105,109]$. The primary objective of this paper is to analyze in detail the dependence on the morphology of BC aerosols of an important optical characteristic called the linear depolarization ratio (LDR). This characteristic is often measured in laboratory experiments $[110,111]$ and, in the case of the exact backscattering direction, in lidar remote-sensing research [112-115], but appears to be studied inadequately on the basis of first-principle numerical computations. Our paper is motivated by the recent publication [98] in which the FDTDM was used to compute the LDR for smoke clusters of up to four monomers in order to analyze implications of depolarization lidar observations from the Cloud-Aerosol Lidar and a

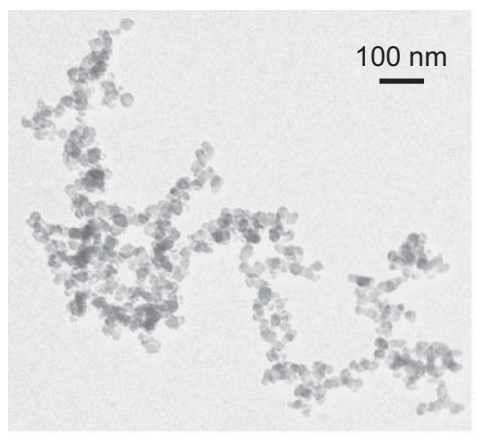

d

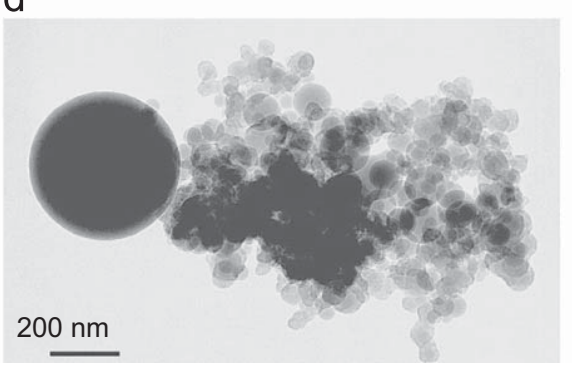

b

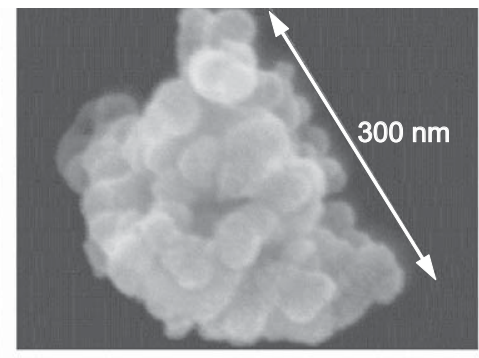

C

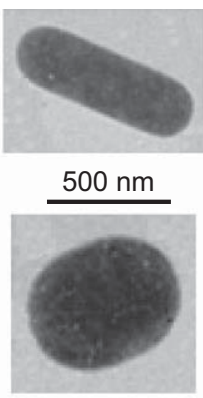

e

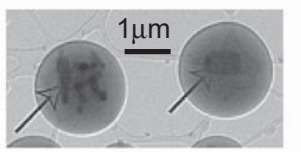

Fig. 1. (a) Transmission electron microscope (TEM) image of a soot cluster [29], (b) Scanning electron microscope image of a collapsed (fractal dimension approaching 3) chamise smoke particle [24], (c) TEM images of nearly spheroidal soot particles [28], (d) TEM image of an aggregate formed by a soot cluster and an ammonium sulfate particle [15] and (e) TEM image of internally mixed soot aggregates. Arrows show solid phases inside aqueous droplets [27]. 
Infrared Pathfinder Satellite Observation (CALIPSO) satellite [115]. We extend the analysis of Ref. [98] by considering a more comprehensive and representative set of soot-particle models and using what we believe to be more relevant refractive indices.

\section{Basic definitions and notation}

The key single-scattering characteristics of randomly oriented particles forming a macroscopically isotropic and mirror-symmetric turbid medium are the ensembleaveraged scattering and extinction cross sections per particle and the elements of the normalized scattering matrix [46]. In the standard $\{I, Q, U, V\}$ representation of polarization, the normalized $4 \times 4$ Stokes scattering matrix has the well-known block-diagonal structure [46]:

$\tilde{\mathbf{F}}(\Theta)=\left[\begin{array}{cccc}a_{1}(\Theta) & b_{1}(\Theta) & 0 & 0 \\ b_{1}(\Theta) & a_{2}(\Theta) & 0 & 0 \\ 0 & 0 & a_{3}(\Theta) & b_{2}(\Theta) \\ 0 & 0 & -b_{2}(\Theta) & a_{4}(\Theta)\end{array}\right]$,

where $0^{\circ} \leq \Theta \leq 180^{\circ}$ is the scattering angle. The $(1,1)$ element of the scattering matrix, $a_{1}(\Theta)$, is traditionally called the phase function, satisfies the normalization condition

$\frac{1}{2} \int_{0}^{\pi} \mathrm{d} \Theta \sin \Theta a_{1}(\Theta)=1$

and describes the angular distribution of the scattered intensity in the case of unpolarized incident light.

If the incident light is polarized linearly in the scattering plane then $Q^{\text {inc }}=I^{\text {inc }}$ and $U^{\text {inc }}=V^{\text {inc }}=0$. It is easily seen that the corresponding angular distributions of the copolarized and cross-polarized scattered intensities are given by

$\frac{1}{2}\left(I^{\mathrm{sca}}+Q^{\mathrm{sca}}\right) \propto \frac{1}{2}\left[a_{1}(\Theta)+2 b_{1}(\Theta)+a_{2}(\Theta)\right]$,

$\frac{1}{2}\left(I^{\mathrm{sca}}-Q^{\mathrm{sca}}\right) \propto \frac{1}{2}\left[a_{1}(\Theta)-a_{2}(\Theta)\right]$.

Therefore, the LDR can be defined according to

$$
\Delta(\Theta)=\frac{a_{1}(\Theta)-a_{2}(\Theta)}{a_{1}(\Theta)+2 b_{1}(\Theta)+a_{2}(\Theta)} .
$$

For spherically symmetric scatterers, the LDR vanishes owing to the identity $a_{1}(\Theta) \equiv a_{2}(\Theta)$. Otherwise it may carry useful implicit information on particle morphological properties.

At exactly the backscattering direction, $b_{1}\left(180^{\circ}\right)=0$, and so

$\Delta\left(180^{\circ}\right)=\frac{a_{1}\left(180^{\circ}\right)-a_{2}\left(180^{\circ}\right)}{a_{1}\left(180^{\circ}\right)+a_{2}\left(180^{\circ}\right)}=\delta_{\mathrm{L}}$,

where $\delta_{\mathrm{L}}$ is the conventional lidar linear depolarization ratio $[46,112-115]$.

\section{Numerical results and discussion}

Using the (superposition) TMM, we calculated the LDR for several BC and BC-containing aerosol morphologies shown in Fig. 2. The fractal aggregate model satisfies the following statistical scaling law $[13,14]$ :

$N=k_{0}\left(\frac{R_{\mathrm{g}}}{a}\right)^{D_{\mathrm{f}}}$,

where $R_{\mathrm{g}}$, called the radius of gyration, is a measure of the overall aggregate radius; the fractal prefactor $k_{0}$ and the fractal dimension $D_{\mathrm{f}}$ define the compactness of the aggregate, higher values corresponding to more compact clusters; $a$ is the mean monomer radius; and $N$ is the number of monomers in the fractal. Fig. $2 b$ and $c$ represents a model of the post-collapse stage in the BC cluster evolution $[17,22,24,43]$, while Fig. 2e and $\mathrm{f}$ are intended to model BC particles shown in Fig. 1c. The practical relevance of the morphology shown in Fig. $2 \mathrm{~d}$ is less certain at this point, but its inclusion in the analysis is justified by the relative ease of modeling and by potentially significant remote-sensing and radiation-budget implications [82].

We first calculated the LDRs for (i) low-density fractal aggregates with a fractal dimension $D_{\mathrm{f}}=1.82$ and prefactor $k_{0}=1.19$, composed of 125 identical BC spherules with a radius $r=20 \mathrm{~nm}$; (ii) $125 \mathrm{BC}$ spherules with a radius $r=20 \mathrm{~nm}$ densely compacted inside a circumscribing sphere with a radius $R_{\mathrm{c}}=150 \mathrm{~nm}$; (iii) $125 \mathrm{BC}$ spherules with a radius $r=20 \mathrm{~nm}$ randomly covering a larger nonabsorbing sulfate particle with a radius of $R_{\mathrm{s}}=150 \mathrm{~nm}$; (iv) an equiprobable shape mixture of externally mixed BC spheroids with axis ratios $1 / 2,1 / 1.8,1 / 1.6,1 / 1.4,1 / 1.2$, $1.2,1.4,1.6,1.8,2$; and (v) an equiprobable shape mixture of externally mixed $\mathrm{BC}$ circular cylinders with diameterto-length ratios $1 / 2,1 / 1.8,1 / 1.6,1 / 1.4,1 / 1.2,1,1.2,1.4$, $1.6,1.8,2$. The wavelength is fixed at $550 \mathrm{~nm}$, the refractive index of the soot particles is $m=1.75+i 0.435$, and the equal-volume-sphere radius $R_{\mathrm{ve}}$ of the BC material is $100 \mathrm{~nm}$ for all five particle morphologies. The latter value represents the effective radius of $\mathrm{BC}$ aerosols
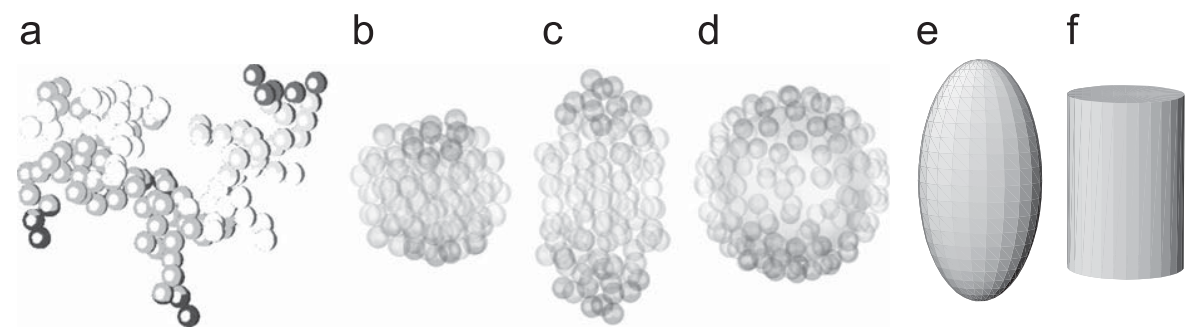

Fig. 2. Simulated soot and soot-containing aerosol habits: (a) fluffy fractal BC aggregates, (b) compact nearly-spherical BC aggregates, (c) compact nearlyspheroidal BC aggregates, (d) host aerosol particles randomly coated with multiple soot spherules, (e) BC spheroids and (f) BC cylinders. 

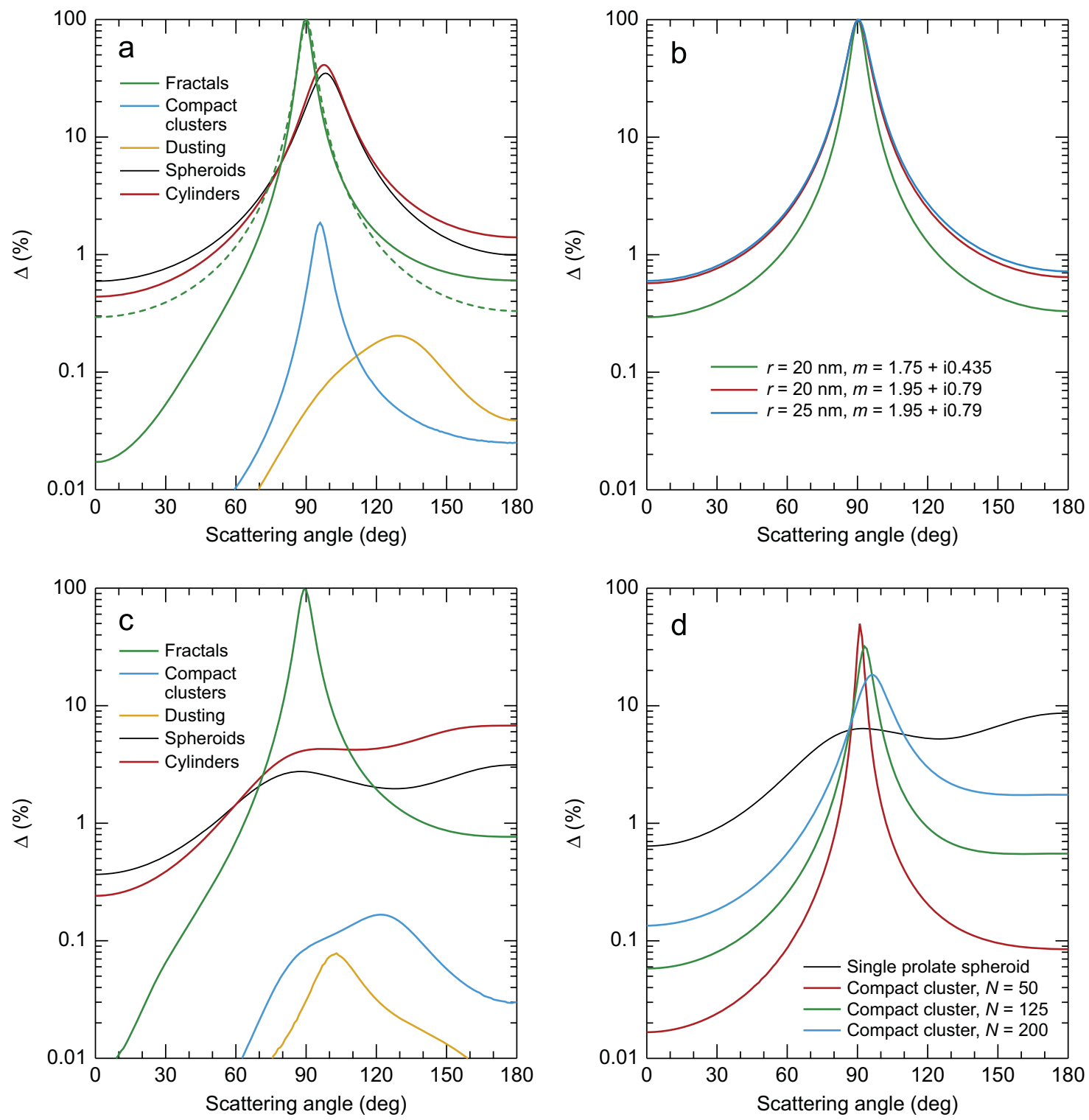

Fig. 3. (a) The solid curves show the LDR (in \%) vs. scattering angle $\Theta$ for nonspherical BC and BC-containing aerosol habits (i)-(v) described in the main text. In all cases the cumulative volume-equivalent-sphere radius $R_{\mathrm{ve}}$ for the $\mathrm{BC}$ material is equal to $100 \mathrm{~nm}$. The dashed green curve reproduces the green curve from panel (b). (b) LDR (in \%) vs. scattering angle $\Theta$ for BC bispheres with identical touching components and in random orientation. (c) As in panel (a) but for $R_{\mathrm{ve}}=150 \mathrm{~nm}$. (d) LDR (in \%) vs. scattering angle $\Theta$ for a single randomly oriented prolate BC spheroid with an aspect ratio of 2 and $R_{\mathrm{ve}}=150 \mathrm{~nm}$ as well as for randomly oriented near-spheroidal clusters built of 20-nm radius BC monomers. In each case the $N$ soot monomers populate a prolate spheroidal volume with the same aspect ratio 2 and $R_{\mathrm{ve}}=150 \mathrm{~nm}$. The BC refractive index is fixed at $1.75+i 0.435$.

adopted in the NASA Goddard Institute for Space Studies general circulation model (A.A. Lacis, personal communication). The results for habits (i)-(iii) in Fig. 3a and c are ensemble-averaged over 10 random realizations of each morphological type in order to provide a more realistic modeling of natural particle mixtures (cf. Refs. [76, 116]) and ensure smooth depolarization curves.

The numerical results for the five nonspherical habits (i)-(v) are shown in Fig. 3a. A remarkable feature of the depolarization curve for the low-density BC fractals is a sharp maximum at $\Theta \approx 90^{\circ}$. To explain this feature, it is instructive to recall the form of the normalized Stokes scattering matrix for randomly oriented Rayleigh particles with an anisotropic polarizability, including those with shape-induced anisotropy [117-119]:

$\tilde{\mathbf{F}}_{\mathrm{R}}(\Theta)=\frac{3}{3 y+1}\left[\begin{array}{cccc}y+\cos ^{2} \Theta & -\sin ^{2} \Theta & 0 & 0 \\ -\sin ^{2} \Theta & 1+\cos ^{2} \Theta & 0 & 0 \\ 0 & 0 & \frac{3}{2} \cos \Theta & 0 \\ 0 & 0 & 0 & \frac{3}{2} \cos \Theta\end{array}\right]$. 
Depending on the particle shape, the parameter $y$ can vary from 1 to 13 , the former value corresponding to spherically symmetric particles. Eqs. (5) and (8) yield the following formula for the Rayleigh LDR:

$\Delta_{\mathrm{R}}(\Theta)=\frac{y-1}{y+1+2 \cos 2 \Theta}$.

It is clear that $\Delta_{R}(\Theta)$ vanishes for spherically symmetric scatterers, but a degree of shape anisotropy causes a symmetric maximum centered at $\Theta \approx 90^{\circ}$.

This conclusion is illustrated in Fig. 4 by depicting $\Delta_{\mathrm{R}}(\Theta)$ for several values of $y$. The Rayleigh LDR behaves like a delta function for $y=1.002$, but the height of the peak relative to the background decreases and its width increases substantially by the time $y$ reaches the value 2 .

We can thus conclude that linear depolarization produced by the low-density BC fractals behaves as that of randomly oriented Rayleigh scatterers with a weakly anisotropic polarizability. This result is not surprising. In the single-scattering approximation, wherein each monomer is assumed to be excited only by the incident field (see Chapter 7 of Ref. [120]), the LDR of a BC cluster composed of spherical monomers would be exactly zero. This implies that a non-zero LDR must result from electromagnetic interactions between the monomers [110]. However, the strongly absorbing nature of the $\mathrm{BC}$ monomers acts to suppress multi-monomer interactions, which makes it reasonable to assume that for a fluffy aggregate the non-zero LDR is caused primarily by double-scattering interactions between pairs of adjacent monomers, the size parameter of such monomer doublets still being in the Rayleigh domain. It is thus the shape-induced anisotropic polarizability of these Rayleigh doublets that causes the sharp side-scattering peak in the angular profile of the LDR for fluffy BC fractals.

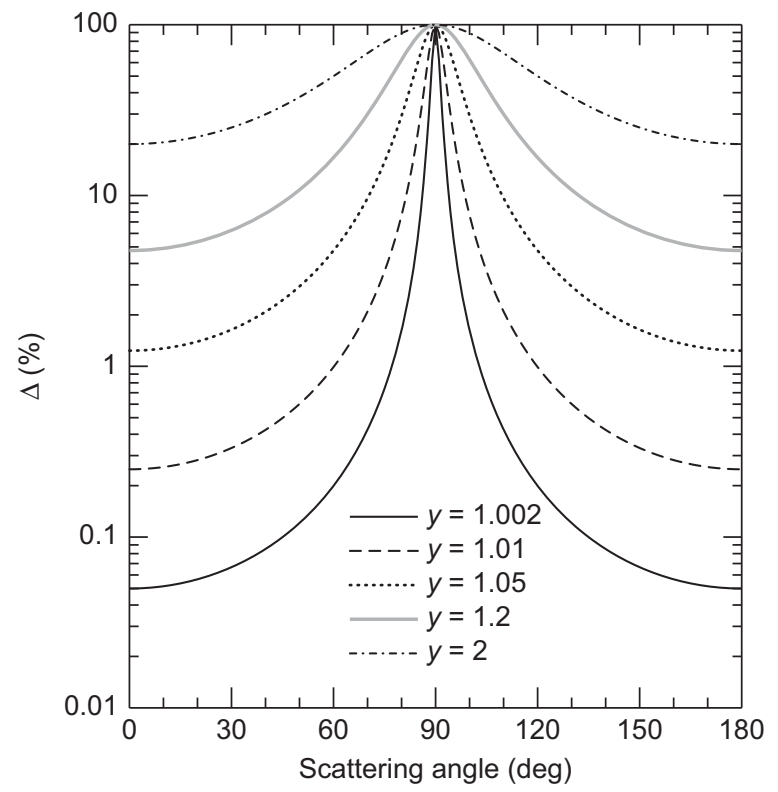

Fig. 4. Linear depolarization $\Delta_{\mathrm{R}}(\Theta)$ (in \%) vs. scattering angle for randomly oriented Rayleigh particles with an anisotropic polarizability.
To substantiate this conclusion, we plot in Fig. 3b the LDRs for two-sphere BC clusters with touching components and in random orientation. Both spheres have the same radius ( 20 or $25 \mathrm{~nm}$ ) and the same refractive index $(1.75+i 0.435$ or $1.95+i 0.79)$. All three LDR curves are almost perfectly symmetric with respect to the $90^{\circ}$ scattering angle and are described by anisotropy parameters $y$ between $\sim 1.01$ and $\sim 1.03$ (cf. Fig. 4). Furthermore, the angular width of the green-curve maximum at the $\Delta=10 \%$ level in Fig. $3 \mathrm{~b}$ is virtually the same as that of the dashed curve in Fig. 4. The green curve from Fig. $3 \mathrm{~b}$ is reproduced as the dashed green curve in Fig. 3a. Although the wings of the two green curves in Fig. 3a diverge owing to the residual effects of multi-monomer interactions in the $N=125$ soot fractal, the angular profiles of the corresponding side-scattering maxima are hardly distinguishable down to the $\Delta \sim 5 \%$ level.

The multi-monomer interactions can be expected to be much stronger in the case of a densely packed $\mathrm{BC}$ aggregate owing to the fact that almost every monomer is now surrounded by many closely positioned monomers rather than being quasi-isolated. As a consequence, the resulting LDR must be affected by the overall shape of the cluster. It is seen indeed from Fig. 3a that packing the same number of $\mathrm{BC}$ monomers into a compact nearly spherical cluster reduces the magnitude of the depolarization maximum by almost two orders of magnitude. The maximum LDR value for habit (iii) is even smaller, owing to the scattering dominance of the large spherical host causing near-zero linear depolarization.

The depolarization curves for the spheroid and cylinder shape mixtures in Fig. 3a are rather close to each other and show the highest $\delta_{\mathrm{L}}$ values. They also reveal pronounced maxima at side-scattering angles which can be explained by the size parameter of the particles still being in the vicinity of the Rayleigh domain.

Fig. 3c parallels Fig. 3a, but the cumulative equalvolume-sphere radius $R_{\mathrm{ve}}$ of the soot material is now $150 \mathrm{~nm}$; the number of monomers in models (i) and (ii) is 422; the radius of the circumscribing sphere in model (ii) is $225 \mathrm{~nm}$; and the radius of the sulfate host in model (iii) is $260 \mathrm{~nm}$. The other fractal parameters of model (i) remain unchanged.

One can see that now the depolarization curves for the spheroid and cylinder mixtures lack the pronounced quasi-Rayleigh maximum at side-scattering angles and reveal significantly increased backscattering values. The likely explanation of this behavior is that the $50 \%$ increase in the particle size moves their size parameter farther from the Rayleigh domain. The curve for the fluffy fractal aggregate is hardly different from that in Fig. 3a, which is consistent with the above explanation of its quasiRayleigh origin. Finally, models (ii) and (iii) produce very low LDR values, which, again, is an expected consequence of strengthened electromagnetic interactions for the nearly spherical model (ii) and increased scattering dominance of the spherical sulfate host in model (iii).

Fig. 5a compares the LDRs for randomly oriented fractal soot aggregates at a wavelength of $550 \mathrm{~nm}$. The fractal parameters $D_{\mathrm{f}}$ and $k_{0}$ are fixed at 1.82 and 1.19 , respectively, thereby representing the mean values 

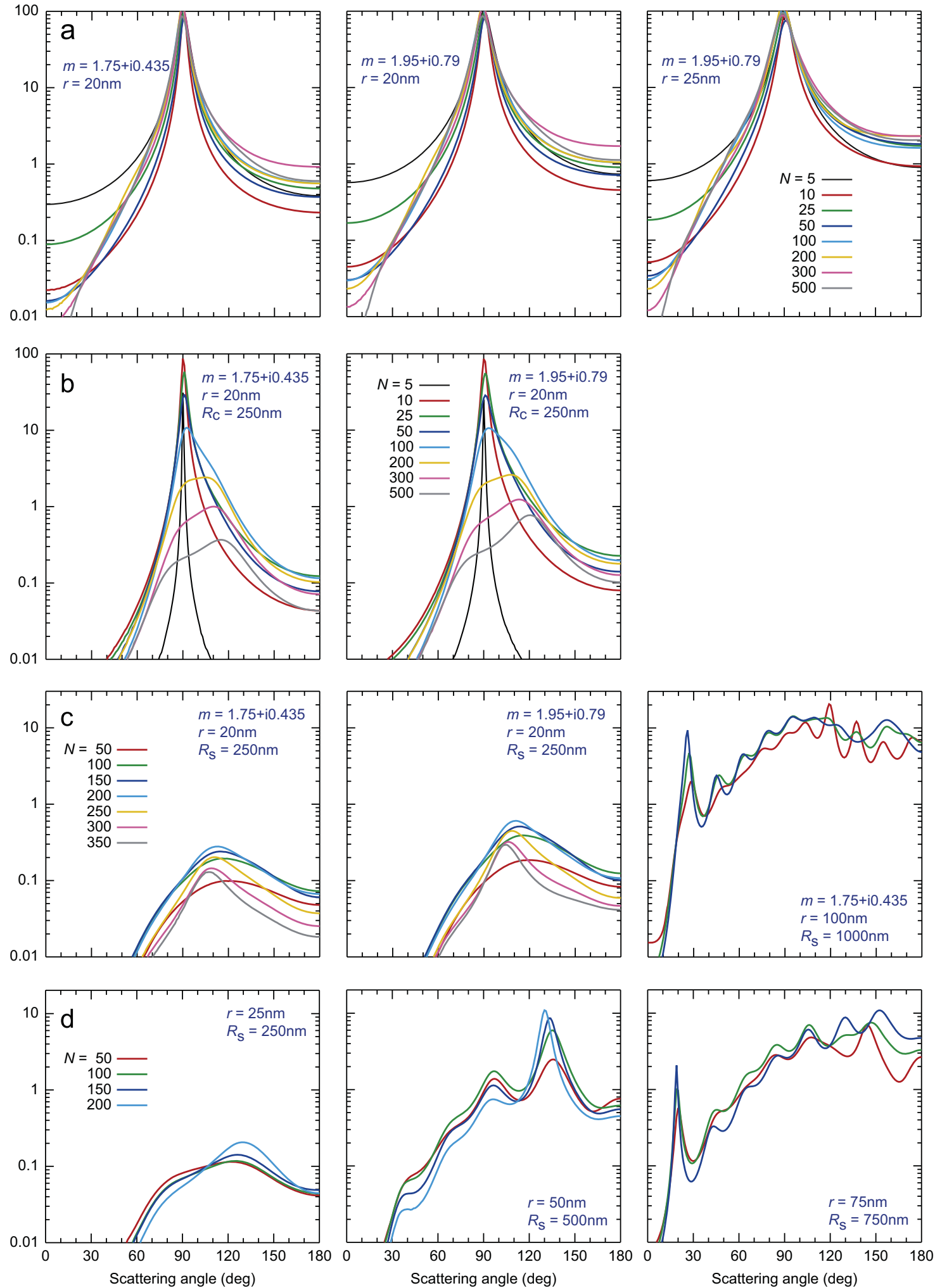

Fig. 5. (a) LDR (in \%) vs. scattering angle $\Theta$ at a wavelength of $550 \mathrm{~nm}$ for different low-density fractal models. (b) As in panel (a), but for groups of $N$ soot monomers uniformly distributed throughout a spherical volume having a radius of $R_{\mathrm{c}}=250 \mathrm{~nm}$. (c) LDRs for a sulfate host randomly coated with $N$ soot spherules. The wavelength is $550 \mathrm{~nm}$ in the left-hand and middle panels and $628 \mathrm{~nm}$ in the right-hand panel. The refractive index of the host sulfate particle is 1.44. (d) LDR increase with increasing $r$ and $R_{\mathrm{s}}$. The wavelength is fixed at $628 \mathrm{~nm}$, and the refractive indices are 1.44 for the sulfate host and $1.75+i 0.435$ for the $\mathrm{BC}$ spherules. 
obtained by Sorensen and Roberts [121] in their diffusionlimited cluster aggregation simulations. The refractive index $m$ is equal to $1.75+i 0.435$ in the left-hand panel and to $1.95+i 0.79$ in the middle and right-hand panels. The BC monomer radius $r$ is equal to $20 \mathrm{~nm}$ in the lefthand and middle panels and increases to $25 \mathrm{~nm}$ in the right-hand panel. The number of monomers in the fluffy fractal clusters varies from 5 to 500 .

Upon realizing that it is difficult in practice to achieve measurement accuracies for $\Delta(\Theta)$ significantly better than a percent, one has to conclude from Fig. 5a that the sensitivity of the LDR to parameters of fluffy BC clusters is rather weak. Perhaps the only detectable manifestation of multi-monomer interactions in the fluffy $\mathrm{BC}$ fractals is the widening of the side-scattering peak with increasing $N$. Also noticeable are larger $\delta_{\mathrm{L}}$ values for the soot clusters with $m=1.95+i 0.79$.

Fig. $5 \mathrm{~b}$ is intended to further test our hypothesis of the quasi-Rayleigh origin of the side-scattering peak in LDR curves for low-density clusters of small BC monomers. The idea is to keep the radius of the circumscribing sphere $R_{\mathrm{c}}$ fixed while increasing the number of uniformly distributed monomers from 5 to 500 , thereby varying the expected packing-density effect on $\Delta(\Theta)$. The wavelength is fixed at $550 \mathrm{~nm}$.

One can see that if $N=5$ then the average distance between the monomers is so large that the electromagnetic interaction between the monomers is weak and cannot cause LDRs approaching $100 \% . N=10$ maximizes the double-scattering contribution and causes LDR values reaching $90 \%$. Further increase in the number of $\mathrm{BC}$ monomers increases the multiple-scattering contribution and eventually results in a densely packed cluster having a nearly spherical shape and LDRs smaller than $1 \%$.

Fig. 3d compares the LDRs for a single randomly oriented prolate $\mathrm{BC}$ spheroid with an aspect ratio of 2 and $R_{\mathrm{ve}}=150 \mathrm{~nm}$ with those for randomly oriented near-spheroidal clusters built of a number $N$ of $20-\mathrm{nm}$ radius BC monomers (see Fig. 2c). In each case the soot monomers are packed into a prolate spheroidal volume with the same aspect ratio 2 and the same equal-volume-sphere radius $R_{\mathrm{ve}}=150 \mathrm{~nm}$ using the cluster-generation procedure described in Ref. [122]. The BC refractive index is taken to be $1.75+i 0.435$. It is seen that with growing $N$, the cluster LDR approaches that of the homogeneous BC spheroid. In particular, the height of the side-scattering maximum decreases while its width increases, and the backscattering LDR significantly increases. These traits are consistent with the growing strength of electromagnetic interactions between multiple densely packed monomers and the resulting dependence of the LDR on the overall cluster nonsphericity.

Fig. 5c and d depicts the LDRs for the aerosol model shown in Fig. 2d, i.e., a larger sulfate particle coated with $N$ soot spherules. One can see that it takes BC spherule radii in excess of $30 \mathrm{~nm}$ to generate LDR values significantly exceeding $1 \%$.

\section{Concluding remarks}

The results of our extensive TMM computations show that the measurement of the LDR over the entire range of scattering angles can be a powerful means of morphological characterization of BC and BC-containing particles. In particular, the detection and profiling of the quasiRayleigh maximum at side-scattering angles can help evaluate the compactness state of $\mathrm{BC}$ clusters and trace the evolution of low-density fluffy fractals into densely packed aggregates. Of course, more research is needed to analyze factors that can potentially influence the uniqueness and accuracy of optical particle characterization based on measurements of the LDR angular profile. In particular, it is unclear whether a priori information on particle chemistry is required and whether a degree of monomer polydispersity can affect data interpretation.

Backscattering lidar measurements can also carry useful information. For example, on the basis of high spectral resolution lidar measurements, Burton et al. [123] have concluded that $\delta_{\mathrm{L}}$ at $532 \mathrm{~nm}$ for fresh smoke is typically very low (less than 2-5\%) and also typically lower than for more aged smoke. This result is consistent with the magnitude and variability of previous lidar observations of smoke by Sassen [112]. The CALIPSO data also showed volume (including molecular and particulate) lidar LDRs $\sim 2 \%$ for South-African smoke [124]. These lidar data are generally consistent with low $\delta_{\mathrm{L}}$ values produced by fluffy fractals in Figs. 3a, c, and 5a as well as by densely packed near-spheroidal aggregates in Fig. 3d. To reproduce larger lidar LDRs typical of the aged smoke (3-8\%), one would need to use alternative particle models such as shape mixtures of $\mathrm{BC}$ spheroids and cylinders and/or large host aerosols covered with relatively large BC spherules. Needless to say, more theoretical and experimental work is still required to draw more definitive conclusions.

\section{Acknowledgments}

We thank W. Patrick Arnott, Rajan Chakrabarty, Hans Moosmüller, and Andrew Lacis for useful discussions and two anonymous referees for constructive and helpful comments. This research was funded by the NASA Radiation Sciences Program managed by Hal Maring and by the NASA Remote Sensing Theory Program managed by Lucia Tsaoussi.

\section{References}

[1] Chýlek P, Lesins GB, Videen G, Wong JGD, Pinnick RG, Ngo D, et al. Black carbon and absorption of solar radiation by clouds. J Geophys Res 1996;101:23365-71.

[2] Hansen JE, Sato M, Ruedy R. Radiative forcing and climate response. J Geophys Res 1997;102:6831-64.

[3] Ackerman AS, Toon OB, Stevens DE, Heymsfield AJ, Ramanathan V, Welton EJ. Reduction of tropical cloudiness by soot. Science 2000;288:1042-7.

[4] Hansen J, Bond T, Cairns B, Gaeggler H, Liepert B, Novakov T, et al. Carbonaceous aerosols in the industrial era. Eos Trans Am Geophys Union 2004;85:241.

[5] Hansen J, Nazarenko L. Soot climate forcing via snow and ice albedos. Proc Natl Acad Sci USA 2004;101:423-8.

[6] Bond TC, Bergstrom RW. Light absorption by carbonaceous particles: an investigative review. Aerosol Sci Technol 2006;40:27-67.

[7] Ramanathan V, Ramana MV, Roberts G, Kim D, Corrigan C, Chung $C$, et al. Warming trends in Asia amplified by brown cloud solar absorption. Nature 2007;448:575-9.

[8] Ramanathan V, Carmichael G. Global and regional climate changes due to black carbon. Nat Geosci 2008;1:221-7. 
[9] Moosmüller H, Chakrabarty RK, Arnott WP. Aerosol light absorption and its measurement: a review. J Quant Spectrosc Radiat Transfer 2009;110:844-78.

[10] Bauer SE, Menon S, Koch D, Bond TC, Tsigaridis K, et al. A global modeling study on carbonaceous aerosol microphysical characteristics and radiative effects. Atmos Chem Phys 2010;10:7439-56.

[11] Koch D, Del Genio AD. Black carbon absorption effects on cloud cover: review and synthesis. Atmos Chem Phys 2010;10:7685-96.

[12] Seinfeld JH, Pandis SN. Atmospheric chemistry and physics: from air pollution to climate change. New York: Wiley; 2006.

[13] Sorensen CM. Light scattering by fractal aggregates: a review. Aerosol Sci Technol 2001;35:648-87.

[14] Mikhailov EF, Vlasenko SS, Kiselev AA. Optics and structure of carbonaceous soot aggregates. In: Markel VA, George TF, editors. Optics of nanostructured materials. Hoboken, NJ: Wiley; 2001. p. $413-66$.

[15] Li J, Anderson JR, Buseck PR. TEM study of aerosol particles from clean and polluted marine boundary layers over the North Atlantic. J Geophys Res 2003;108:4189.

[16] Pósfai M, Simonics R, Li J, Hobbs PV, Buseck PR. Individual aerosol particles from biomass burning in southern Africa. 1. Compositions and size distributions of carbonaceous particles. J Geophys Res 2003;108:8483.

[17] Abel SJ, Haywood JM, Highwood EJ, Li J, Buseck PR. Evolution of biomass burning aerosol properties from an agricultural fire in southern Africa. Geophys Res Lett 2003;30:1783.

[18] Pósfai M, Gelencsér A, Simonics R, Arató K, Li J, Hobbs PV, Buseck PR. Atmospheric tar balls: particles from biomass and biofuel burning. J Geophys Res 2004;109:D06213.

[19] Jones AR. Light scattering in combustion. Light Scattering Rev 2006;1:393-444.

[20] Chakrabarty RK, Moosmüller H, Garro MA, Arnott WP, Walker J, Susott RA, et al. Emissions from the laboratory combustion of wildland fuels: particle morphology and size. J Geophys Res 2006;111:D07204.

[21] Adachi K, Chung SH, Friedrich H, Buseck PR. Fractal parameters of individual soot particles determined using electron tomography: implications for optical properties. J Geophys Res 2007;112: D14202.

[22] Zhang R, Khalizov AF, Pagels J, Zhang D, Xue H, McMurry PH. Variability in morphology, hygroscopicity, and optical properties of soot aerosols during atmospheric processing. Proc Natl Acad Sci USA 2008;105:10291-6.

[23] Worringen A, Ebert M, Th Trautmann, Weinbruch S, Helas G. Optical properties of internally mixed ammonium sulfate and soot particles-a study of individual aerosol particles and ambient aerosol populations. Appl Opt 2008;47:3835-45.

[24] Lewis KA, Arnott WP, Moosmüller H, Chakrabarty RK, Carrico CM, Kreidenweis SM, et al. Reduction in biomass burning aerosol light absorption upon humidification: roles of inorganically-induced hygroscopicity, particle collapse, and photoacoustic heat and mass transfer. Atmos Chem Phys 2009;9:8949-66.

[25] Chakrabarty RK, Moosmüller H, Chen L-WA, Lewis K, Arnott WP, Mazzoleni $\mathrm{C}$, et al. Brown carbon in tar balls from smoldering biomass combustion. Atmos Chem Phys 2010;10:6363-70.

[26] Adachi K, Chung SH, Buseck PR. Shapes of soot aerosol particles and implications for their effects on climate. J Geophys Res 2010;115:D15206.

[27] Freney EJ, Adachi K, Buseck PR. Internally mixed atmospheric aerosol particles: hygroscopic growth and light scattering. J Geophys Res 2010;115:D19210.

[28] Ueda S, Osada K, Takami A. Morphological features of sootcontaining particles internally mixed with water-soluble materials in continental outflow observed at Cape Hedo, Okinawa, Japan. J Geophys Res 2011;116:D17207.

[29] Burr DW, Daun KJ, Thomson KA, Smallwood GJ. Optimization of measurement angles for soot aggregate sizing by elastic light scattering, through design-of-experiment theory. J Quant Spectrosc Radiat Transfer 2012;113:355-65.

[30] Chakrabarty RK, Moosmüller H, Garro MA, Stipe CB. Observation of superaggregates from a reversed gravity low-sooting flame. Aerosol Sci Technol 2012;46:i-iii.

[31] Hansen J, Rossow W, Carlson B, Lacis A, Travis L, Del Genio A, et al. Low-cost long-term monitoring of global climate forcings and feedbacks. Clim Change 1995;31:247-71.

[32] Schwartz SE. Uncertainty requirements in radiative forcing of climate change. J Air Waste Manage Assoc 2004;54:1351-9.

[33] Mishchenko MI, Cairns B, Hansen JE, Travis LD, Burg R, Kaufman YJ, et al. Monitoring of aerosol forcing of climate from space: analysis of measurement requirements. J Quant Spectrosc Radiat Transfer 2004;88:149-61.

[34] IPCC Summary for policymakers. In: Solomon S, Qin D, Manning M, Chen Z, Marquis M, Averyt KB, Tignor M, Miller HL, editors. Climate change 2007: the physical science basis. Cambridge, UK: Cambridge University Press; 2007.

[35] Kiehl JT. Twentieth century climate model response and climate sensitivity. Geophys Res Lett 2007;34:L22710.

[36] Stier P, Seinfeld JH, Kinne S, Boucher O. Aerosol absorption and radiative forcing. Atmos Chem Phys 2007;7:5237-61.

[37] Mishchenko MI, Cairns B, Kopp G, Travis LD, Kopp G, Schueler CF, et al. Accurate monitoring of terrestrial aerosols and total solar irradiance: introducing the Glory Mission. Bull Am Meteorol Soc 2007;88:677-91.

[38] Loeb NG, Su W. Direct aerosol radiative forcing uncertainty based on a radiative perturbation analysis. J Clim 2010;23:5288-93.

[39] Lohmann U, Ferrachat S. Impact of parametric uncertainties on the present-day climate and on the anthropogenic aerosol effect. Atmos Chem Phys 2010;10:11373-83.

[40] Penner JE, Xu L, Wang M. Satellite methods underestimate indirect climate forcing by aerosols. Proc Natl Acad Sci USA 2011;108:13404-8.

[41] Hansen J, Sato M, Kharecha P, von Schuckmann K. Earth's energy imbalance and implications. Atmos Chem Phys 2011(11):13421-49.

[42] Cairns B, Mishchenko MI, editors. The need for aerosol and cloud measurements from space: essential contributions from a rapid reflight of the Aerosol Polarimetry Sensor. New York: NASA Goddard Institute for Space Studies; 2012 〈http://glory.giss.nasa.gov/ APS-2_Report.pdf $>$.

[43] Schnaiter M, Horvath H, Möhler O, Naumann K-H, Saathoff H, Schöck OW, et al. UV-VIS-NIR spectral optical properties of soot and soot-containing aerosols. J Aerosol Sci 2003;34:1421-44.

[44] Mishchenko MI, Liu L, Travis LD, Lacis AA. Scattering and radiative properties of semi-external versus external mixtures of different aerosol types. J Quant Spectrosc Radiat Transfer 2004;88:139-47.

[45] Mishchenko MI, Wiscombe WJ, Hovenier JW, Travis LD. Overview of scattering by nonspherical particles. In: Mishchenko MI, Hovenier JW, Travis LD, editors. Light scattering by nonspherical particles: theory, measurements, and applications. San Diego: Academic Press; 2000. p. 29-60.

[46] Mishchenko MI, Travis LD, Lacis AA. Scattering, absorption, and emission of light by small particles. Cambridge: Cambridge University Press; $2002<$ http://www.giss.nasa.gov/ crmim/books. html $>$.

[47] Kahnert FM. Numerical methods in electromagnetic scattering theory. J Quant Spectrosc Radiat Transfer 2003;79-80:775-824.

[48] Wriedt Th. Light scattering theory and programs: discussion of latest advances and open problems. J Quant Spectrosc Radiat Transfer 2012;113:2465-9.

[49] Waterman PC. Symmetry, unitarity, and geometry in electromagnetic scattering. Phys Rev D 1971;3:825-39.

[50] Fuller KA, Mackowski DW. Electromagnetic scattering by compounded spherical particles. In: Mishchenko MI, Hovenier JW, Travis LD, editors. Light scattering by nonspherical particles: theory, measurements, and applications. San Diego: Academic Press; 2000. p. 225-72.

[51] Doicu A, Wriedt T, Eremin YuA. Light scattering by systems of particles. Null-field method with discrete sources: theory and programs. Berlin: Springer; 2006.

[52] Borghese F, Denti P, Saija R. Scattering from model nonspherical particles. Theory and applications to environmental physics. Berlin: Springer; 2007.

[53] Quinten M. Optical properties of nanoparticle systems: Mie and beyond. Weinheim, Germany: Wiley-VCH; 2011.

[54] Fikioris JG, Waterman PC. Multiple scattering of waves. III. The electromagnetic case. J Quant Spectrosc Radiat Transfer, http://dx.doi.org/10.1016/j.jqsrt.2012.09.007, this issue.

[55] Mackowski D. The extension of Mie theory to multiple spheres. In: Hergert W, Wriedt Th, editors. The Mie theory. Berlin: Springer; 2012. p. 223-56.

[56] Draine BT. The discrete dipole approximation for light scattering by irregular targets. In: Mishchenko MI, Hovenier JW, Travis LD, editors. Light scattering by nonspherical particles: theory, measurements, and applications. San Diego: Academic Press; 2000. p. 131-45.

[57] Yurkin MA, Hoekstra AG. The discrete-dipole-approximation code ADDA: capabilities and known limitations. J Quant Spectrosc Radiat Transfer 2011;112:2234-47.

[58] Iskander MF, Chen HY, Penner JE. Optical scattering and absorption by branched chains of aerosols. Appl Opt 1989;28:3083-91. 
[59] Manickavasagam S, Mengüc MP. Scattering matrix elements of fractal-like soot agglomerates. Appl Opt 1997;36:1337-51.

[60] Fuller KA, Malm WC, Kreidenweis SM. Effects of mixing on extinction by carbonaceous particles. J Geophys Res 1999;104:15941-54.

[61] Quinten M, Kreibig U, Henning T, Mutschke H. Wavelengthdependent optical extinction of carbonaceous particles in atmospheric aerosols and interstellar dust. Appl Opt 2002;41:7102-13.

[62] Riefler N, di Stasio S, Wriedt T. Structural analysis of clusters using configurational and orientational averaging in light scattering analysis. J Quant Spectrosc Radiat Transfer 2004;89:323-42.

[63] Ioannidou MP. Study of atmospheric visibility pertaining to soot scavenging by sulfate droplets. J Quant Spectrosc Radiat Transfer 2005;96:473-85.

[64] Liu L, Mishchenko MI. Effects of aggregation on scattering and radiative properties of soot aerosols. J Geophys Res 2005;110: D11211.

[65] Liu L, Mishchenko MI. Scattering and radiative properties of complex soot and soot-containing aggregate particles. J Quant Spectrosc Radiat Transfer 2007; 106:262-73.

[66] Liu L, Mishchenko MI, Arnott WP. A study of radiative properties of fractal soot aggregates using the superposition T-matrix method. J Quant Spectrosc Radiat Transfer 2008;109:2656-63.

[67] Zhao Y, Ma L. Assessment of two fractal scattering models for the prediction of the optical characteristics of soot aggregates. J Quant Spectrosc Radiat Transfer 2009;110:315-22.

[68] Wagner R, Linke C, Naumann K-H, Schnaiter M, Vragel M, Gangl M, et al. A review of optical measurements at the aerosol and cloud chamber AIDA. J Quant Spectrosc Radiat Transfer 2009;110:930-49.

[69] Zhao Y, Ma L. Applicable range of the Rayleigh-Debye-Gans theory for calculating the scattering matrix of soot aggregates. Appl Opt 2009;48:591-7.

[70] Kahnert M. On the discrepancy between modeled and measured mass absorption cross sections of light absorbing carbon aerosols. Aerosol Sci Technol 2010;44:453-60.

[71] Kahnert M. Modelling the optical and radiative properties of freshly emitted light absorbing carbon within an atmospheric chemical transport model. Atmos Chem Phys 2010;10:1403-16.

[72] Kahnert M. Numerically exact computation of the optical properties of light absorbing carbon aggregates for wavelength of $200 \mathrm{~nm}-12.2 \mu \mathrm{m}$. Atmos Chem Phys 2010;10:8319-29.

[73] Liu F, Smallwood GJ. Effect of aggregation on the absorption crosssection of fractal soot aggregates and its impact on LII modelling. J Quant Spectrosc Radiat Transfer 2010;111:302-8.

[74] Yin JY, Liu LH. Influence of complex component and particle polydispersity on radiative properties of soot aggregate in atmosphere. J Quant Spectrosc Radiat Transfer 2010;111:2115-26.

[75] Li H, Liu C, Yang P, Bi L, Kattawar GW, et al. Numerical accuracy of equivalent spherical approximations for computing ensembleaveraged scattering properties of fractal soot aggregates. J Quant Spectrosc Radiat Transfer 2010;111:2127-32.

[76] Liu F, Smallwood GJ. Radiative properties of numerically generated fractal soot aggregates: the importance of configuration averaging. J Heat Transfer 2010;132:023308.

[77] Yin JY, Liu LH. Radiative property of multi-particle soot cluster formed by different diameter and component. Am Inst Phys Conf Proc 2010;1207:598-603.

[78] Liu F, Smallwood GJ. The effect of particle aggregation on the absorption and emission properties of mono- and polydisperse soot aggregates. Appl Phys B 2011;104:343-55.

[79] Kahnert M, Devasthale A. Black carbon fractal morphology and short-wave radiative impact: a modelling study. Atmos Chem Phys 2011;11:11745-59.

[80] Ma L. Analysis of error in soot characterization using scatteringbased techniques. Particuology 2011;9:210-4.

[81] Liu C, Panetta RL, Yang P. The influence of water coating on the optical scattering properties of fractal soot aggregates. Aerosol Sci Technol 2012;46:31-43.

[82] Mishchenko MI, Dlugach JM. Adhesion of mineral and soot aerosols can strongly affect their scattering and absorption properties. Opt Lett 2012;37:704-6.

[83] Chung CE, Lee K, Müller D. Effect of internal mixture on black carbon radiative forcing. Tellus B 2012;64:10925.

[84] Mishra SK, Tripathi SN, Aggarwal SG. Optical properties of accumulation mode, polluted mineral dust: effects of particle shape, hematite content and semi-external mixing with carbonateous species. Tellus B 2012;64:18536.

[85] Wu Y, Gu X, Cheng T, Xie D, Yu T, Chen H, et al. The single scattering properties of the aerosol particles as aggregated spheres. J Quant Spectrosc Radiat Transfer 2012;113:1454-66.
[86] Zhang Y, Deng X, Li Y, Sun W, Zhang Y. Comparative study on polydisperse and monodisperse smoke particles for light scattering model. Chinese J Lasers 2012;39:0408004.

[87] Skorupski K, Mroczka J, Riefler N, Oltmann H, Will S, Wriedt Th. et al. Impact of morphological parameters onto simulated light scattering patterns. J Quant Spectrosc Radiat Transfer, submitted for publication.

[88] Chen HY, Iskander MF, Penner JE. Light scattering and absorption by fractal agglomerates and coagulations of smoke aerosols. J Mod Opt 1990;37:171-81

[89] Mengüç MP, Manickavasagam S. Characterization of size and structure of agglomerates and inhomogeneous particles via polarized light. Int J Eng Sci 1998;36:1569-93.

[90] Van-Hulle P, Weill M-E, Talbaut M, Coppalle A. Comparison of numerical studies characterizing optical properties of soot aggregates for improved EXSCA measurements. Part Part Syst Charact 2002;19:47-57.

[91] Klusek C, Manickavasagam S, Mengüç MP. Compendium of scattering matrix element profiles for soot agglomerates. J Quant Spectrosc Radiat Transfer 2003;79-80:839-59.

[92] Scarnato B, Vahidinia S, Richard DT, Kirchstetter TW. Effects of internal mixing and aggregate morphology on optical properties of black carbon using a discrete dipole approximation model. Atmos Chem Phys Discuss 2012;12:26401-34.

[93] Kahnert M, Nousiainen T, Lindqvist H, Ebert M. Optical properties of light absorbing carbon aggregates mixed with sulfate: assessment of different model geometries for climate forcing calculations. Opt Express 2012;20:10042-58.

[94] Lei C, Feng D. Study of scattering and radiative properties of complex soot aggregates. Chinese Opt Lett 2012;10(Suppl):S12901.

[95] Bescond A, Yon J, Girasole C, Jouen C, Rozé C, Coppalle A Numerical investigation of the possibility to determine the primary particle size of fractal aggregates by measuring light depolarization. J Quant Spectrosc Radiat Transfer, http://dx.doi. org/10.1016/j.jqsrt.2012.10.011, in press.

[96] Yang P, Liou KN. Finite difference time domain method for light scattering by nonspherical and inhomogeneous particles. In: Mishchenko MI, Hovenier JW, Travis LD, editors. Light scattering by nonspherical particles: theory, measurements, and applications. San Diego: Academic Press; 2000. p. 173-221.

[97] Sun W, Videen G, Fu Q, Tanev S, Lin B, Hu Y, et al. Finite-difference time-domain solution of light scattering by arbitrarily shaped particles and surfaces. Light Scattering Rev 2012;6:75-113.

[98] Sun W, Liu Zh, Videen G, Fu Q, Muinonen K, Winker DM, et al. For the depolarization of linearly polarized light by smoke particles. J Quant Spectrosc Radiat Transfer, http://dx.doi.org/10.1016/j.jqsrt. 2012.03.031, in press.

[99] Liu C, Panetta RL, Yang P. Application of the pseudo-spectral time domain method to compute particle single-scattering properties for size parameters up to 200. J Quant Spectrosc Radiat Transfer 2012;113:1728-40.

[100] Liu C, Bi L, Panetta RL, Yang P, Yurkin MA. Comparison between the pseudo-spectral time domain method and the discrete dipole approximation for light scattering simulations. Opt Express 2012;20:16763-6.

[101] Cui ZW, Han YP, Li CY. Characterization of the light scattering by ensembles of randomly distributed soot aggregates. J Quant Spectrosc Radiat Transfer 2011;112:2722-32.

[102] Cui ZW, Han YP, Wang JJ, Zhao WJ. Scattering of Gaussian beam by arbitrarily shaped inhomogeneous particle. J Quant Spectrosc Radiat Transfer 2012;113:480-8.

[103] Han YP, Cui ZW, Gouesbet G. Numerical simulation of Gaussian beam scattering by complex particles of arbitrary shape and structure. J Quant Spectrosc Radiat Transfer 2012;113:1719-72.

[104] Cui Z, Han Y, Zhao W. Scattering of arbitrarily incident Gaussian beams by fractal soot aggregates. J Opt 2012;14:035703.

[105] Mackowski DW, Mishchenko MI. A multiple sphere T-matrix Fortran code for use on parallel computer clusters. J Quant Spectrosc Radiat Transfer 2011;112:2182-92.

[106] Boyde L, Chalut KJ, Guck J. Near- and far-field scattering from arbitrary three-dimensional aggregates of coated spheres using parallel computing. Phys Rev E 2011;83:026701.

[107] Kahnert M. The T-matrix code Tsym for homogeneous dielectric particles with finite symmetries. J Quant Spectrosc Radiat Transfer, accepted for publication.

[108] Mackowski DW, Mishchenko MI. Calculation of the $T$ matrix and the scattering matrix for ensembles of spheres. J Opt Soc Am A 1996;13:2266-78.

[109] Mackowski DW. The multiple sphere T-matrix Fortran-90 code. $\langle$ http://eng.auburn.edu/users/dmckwski/scatcodes $\rangle$. 
[110] Lu N, Sorensen CM. Depolarized light scattering from fractal soot aggregates. Phys Rev E 1994;50:3109-15.

[111] di Stasio S. Experiments on depolarized optical scattering to sense in situ the onset of early agglomeration between nano-size soot particles. J Quant Spectrosc Radiat Transfer 2002;73:423-32.

[112] Sassen K. Lidar backscatter depolarization technique for cloud and aerosol research. In: Mishchenko MI, Hovenier JW, Travis LD, editors. Light scattering by nonspherical particles: theory, measurements, and applications. San Diego: Academic Press; 2000. p. 393-416.

[113] Roy G, Cao X, Bernier R. On linear and circular depolarization LIDAR signatures in remote sensing of bioaerosols: experimental validation of the Mueller matrix for randomly oriented particles. Opt Eng 2011;50:126001.

[114] David G, Miffre A, Thomas B, Rairoux P. Sensitive and accurate dual-wavelength UV-VIS polarization detector for optical remote sensing of tropospheric aerosols. Appl Phys B 2012;108: 197-216.

[115] Winker DM, Pelon J, Coakley Jr. JA, Ackerman SA, Charlson RJ, Colarco PR, et al. The CALIPSO Mission: a global 3D view of aerosols and clouds. Bull Am Meteorol Soc 2010;91:1211-29.

[116] Kolokolova L, Kimura H, Ziegler K, Mann I. Light-scattering properties of random-oriented aggregates: do they represent the properties of an ensemble of aggregates? J Quant Spectrosc Radiat Transfer 2006;100:199-206.

[117] van de Hulst HC. Light scattering by small particles. New York: Wiley; 1957.

[118] Bohren CF, Huffman DR. Absorption and scattering of light by small particles. New York: Wiley; 1983.

[119] Kokhanovsky AA. Polarization optics of random media. Chichester, UK: Praxis; 2003.

[120] Mishchenko MI, Travis LD, Lacis AA. Multiple scattering of light by particles: radiative transfer and coherent backscattering. Cambridge: Cambridge University Press; $2006<$ http://www.giss.nasa. gov/staff/mmishchenko/publications/Book3.pdf $\rangle$.

[121] Sorensen CM, Roberts GC. The prefactor of fractal aggregates. J Colloid Interface Sci 1997;186:447-52.

[122] Dlugach JM, Mishchenko MI, Mackowski DW. Numerical simulations of single and multiple scattering by fractal ice clusters. J Quant Spectrosc Radiat Transfer 2011;112:1864-70.

[123] Burton SP, Ferrare RA, Hostetler CA. Aerosol classification using airborne High Spectral Resolution Lidar measurementsmethodology and examples. Atmos Meas Tech 2012;5:73-98.

[124] Winker DM, Hunt WH, McGill MJ. Initial performance assessment of CALIOP. Geophys Res Lett 2007;34:L19803. 